ORIGINAL ARTICLE

\title{
Non-expert use of the cerebral function monitor for neonatal seizure detection
}

\author{
J M Rennie, G Chorley, G B Boylan, R Pressler, Y Nguyen, R Hooper
}

Arch Dis Child Fetal Neonatal Ed 2004;89:F37-F40

See end of article for authors' affiliations ......................

Correspondence to: Dr Rennie Neonatal Unit, King's College Hospital, Denmark Hill, London SE5 9RS, UK; janet.rennie@ kcl.ac.uk

Accepted 2 December 2002
Background: The cerebral function monitor (CFM) is widely used to detect neonatal seizures, but there are very few studies comparing it with simultaneous electroencephalography (EEG).

Objective: To determine the accuracy of non-expert use of the CFM and to assess interobserver agreement of CFM seizure detection.

Patients: Babies admitted to the neonatal intensive care unit at King's College Hospital who were at high risk of seizure and had video-EEG monitoring.

Methods: Video-EEG was used to detect seizures. Each baby had CFM recordings at speeds of 6, 15, and $30 \mathrm{~cm} / \mathrm{h}$ during the EEG. Four neonatologists, trained in CFM seizure recognition, independently rated one hour CFM samples at three speeds from each baby. Interobserver agreement was quantified using Cohen's $K$.

Results: CFM traces from 19 babies with EEG seizures and 21 babies without EEG seizures were analysed. Overall non-expert interpretation of the CFM performed poorly as a seizure detector compared with simultaneous EEG (sensitivities $38 \%$ at $6 \mathrm{~cm} / \mathrm{h} ; 54 \%$ at $15 \mathrm{~cm} / \mathrm{h} ; 55 \%$ at $30 \mathrm{~cm} / \mathrm{h}$ ). Although babies with seizures were more likely to be correctly classified at higher speeds ( $p=0.02$ ), babies without seizures were also more likely to be misclassified ( $p<0.001$ ). Agreement between observers was not good at any speed ( $\kappa$ values from 0.01 to 0.39 ). The observers usually detected generalised seizures but often missed seizures that were focal, low amplitude, or lasted less than one minute.

Conclusion: Approximately half of all neonatal seizures may be missed using CFM alone. Neonatal seizures need to be diagnosed, characterised, and quantified first using EEG. The CFM may then be useful for long term monitoring.
$\mathrm{T}$ he immature central nervous system is particularly susceptible to seizures, which are the most common clinical presentation of neonatal neurological illness. Neonatal seizures are usually subtle, with motor automatisms which include lip smacking, chewing, blinking, and forced eye opening. There is considerable similarity to normal neonatal behaviour, which makes diagnosis difficult. Apnoea is a common clinical problem in neonates, and on occasion is the only manifestation of seizure. Recognition of seizures is important in order to institute appropriate investigations, counsel parents about prognosis, and monitor treatment. Neonatal seizures may have an adverse effect on neurodevelopmental prognosis, and predispose to cognitive, behavioural, or epileptic complications later in life. ${ }^{1}$ Videoelectroencephalography (EEG) is the optimum method with which to identify, classify, and quantify neonatal seizures. ${ }^{2}$ Video-EEG equipment is expensive, and highly specalised technical and medical support is required to record and interpret the EEG traces. As a result, many neonatal units rely entirely on the cerebral function monitor (CFM) to assist in seizure recognition. The CFM displays the amplitude integrated EEG from one channel in a compressed, rectified, and filtered form on a semilogarithmic scale. Originally invented for monitoring head injured adults in $1969,{ }^{3}$ the patterns of recording from normal and asphyxiated babies have been described by several groups over the years. ${ }^{4-7}$ The CFM is primarily used by clinicians, who in general have no training in EEG analysis, and are given minimal training in reading CFM traces. There have been remarkably few evaluations of the CFM as a seizure detector, its main clinical role. ${ }^{8}{ }^{9}$ We performed such an evaluation in neonates.

\section{METHODS}

\section{Subjects and recordings}

Babies admitted to the neonatal unit at King's College Hospital, London who were at high risk of seizures were studied with video-EEG. This was done in order to recognise babies with seizures whose parents might allow them to take part in our open study of anticonvulsant treatment. Our video-EEG studies had full ethical approval, and parents gave their written informed consent. Babies considered to be at high risk were those with birth depression, meningitis, clinically suspected seizures, or known cerebral pathology.

The diagnosis of an electrographic seizure required the evolution of sudden, repetitive, evolving stereotyped forms with a definite beginning, middle, and end. ${ }^{10} \mathrm{~A}$ minimal ictal duration of 10 seconds was used for this study. Neonatal status epilepticus was defined as continuous seizure activity for at least 30 minutes or recurrent seizures for more than $50 \%$ of the entire recording duration. ${ }^{11}$ Background activity of the EEG was classified according to a scheme that has been defined previously. ${ }^{12}$

From our studies, we identified 19 babies whose video-EEG recording showed seizures. The 19 cases were chosen to be representative of the range of neonatal electrographic seizure types and the underlying causes for seizure. Twenty one control recordings (without seizures) were also identified; nine were from the babies with seizures once the seizures

Abbreviations: EEG, electroencephalography; CFM, cerebral function monitor 
were fully controlled, and 12 were from babies who never had seizures identified.

A Telefactor Beehive Video-EEG system was used to record 12 channels of EEG using the 10-20 system of electrode placement modified for neonates. This system records the video-EEG on to video tape as well as the analogue EEG signal as encoded data. The analogue EEG was then replayed from the video tape, and one channel (P4-P3) was diverted through a Lectromed CFM in order to make simultaneous duplicate recordings. The output from the Telefactor system was stepped down using a simple voltage divider (ratio $1: 1000)$, and the input range to the CFM was fine tuned further by adjusting the montage sensitivity. To ensure accurate transfer of signals, a $50 \mu \mathrm{V}$ calibration signal was introduced to the EEG system using a Telefactor external calibrator (Telefactor Corp calibrator), and the output was measured on the Lectromed CFM. The CFM traces were recorded at three speeds: $1 \mathrm{~mm} / \mathrm{min}(6 \mathrm{~cm} / \mathrm{h}), 2.5 \mathrm{~mm} / \mathrm{min}$ $(15 \mathrm{~cm} / \mathrm{h})$, and $5 \mathrm{~mm} / \mathrm{min}(30 \mathrm{~cm} / \mathrm{h})$. The slowest speed is usually chosen in clinical use.

\section{Observers}

We recruited four volunteers from the unit's medical staff. These neonatologists had no special knowledge of EEG and no previous experience in reading CFM traces. All observers had training sessions on an individual basis. The process of CFM interpretation was explained to each observer using a pack containing 20 interpreted CFM traces with and without seizures. Each observer was allowed to ask as many questions as required on interpretative methods. The time allotted to each observer was determined by the time required for each observer to fully understand the interpretative process but was generally between three and five hours. All CFM recordings in the pack had simultaneous EEG recordings, and the EEG report was also available. Once trained, each observer evaluated 120 anonymous CFM traces, 19 from seizure cases and 21 from controls, at each of the three speeds. The traces were in random order and there was no conferring. The observers had no time constraint, and each observer had full access to their training pack for reference during the evaluation.

\section{Statistical analysis}

Analyses were performed using Stata 7 (Stata Corporation, College Station, Texas, USA). Sensitivities and specificities were calculated as an average over all subjects and all raters. The effects of recording speed on sensitivity and specificity were tested using conditional fixed effects logistic regression. Interrater agreement was quantified using Cohens's $\kappa$, calculated separately for babies with and without seizure, at each speed, and assuming no consistent effects of raters.

\section{RESULTS}

Table 1 gives information about the seizure type and number, background EEG, underlying diagnosis, gestational age, and birth weight of the babies with seizures. The gestational age range at the time of recording was 24-42 weeks, with a mean of 35 weeks. The major diagnostic categories were hypoxic ischaemic encephalopathy, intraventricular haemorrhage, and meningitis. The control babies without seizures also had a mean gestational age of 35 weeks (range 26-42).

Half the records contained more than 10 seizures an hour, and most of the seizures were generalised or became generalised. Three babies were in status epilepticus. In four babies (cases 2, 10, 15, and 18 in table 1), the seizures were only ever focal, but in one of these (baby 18) the focus involved the parietal region, and the seizures should have been reflected in the CFM trace. As expected in a high risk population of babies with seizures, the background EEG was abnormal in most cases.

Tables 2 and 3 show monitoring performed at different speeds. Sensitivity and specificity were each affected by recording speed $\left(\chi^{2}=7.85, \mathrm{df}=2, \mathrm{p}=0.020 ; \chi^{2}=23.6\right.$, $\mathrm{df}=2, \mathrm{p}<0.001$ respectively): babies with seizures were more likely to be correctly classified at higher speeds, but babies without seizures were also more likely to be misclassified (table 2). There was poor interrater agreement at all three speeds. Of the 19 babies with seizures, only four were correctly identified by all four observers. Three of these babies were obviously fitting clinically, and had EEG seizures that were generalised and of more than one minute's duration, and the fourth baby was paralysed for ventilation but was in status epilepticus with high amplitude seizures.

Table 1 Information about the babies with seizures, including their EEG seizure type and number

\begin{tabular}{|c|c|c|c|c|c|c|c|}
\hline $\begin{array}{l}\text { Case } \\
\text { number }\end{array}$ & $\begin{array}{l}\text { Gestation at } \\
\text { birth (weeks) }\end{array}$ & $\begin{array}{l}\text { Birth weight } \\
\text { (g) }\end{array}$ & $\begin{array}{l}\text { Gestation at } \\
\text { EEG (weeks) }\end{array}$ & Diagnosis & EEG background & EEG seizure type & $\begin{array}{l}\text { Number of } \\
\text { seizures per hour }\end{array}$ \\
\hline 1 & 28 & 648 & 29 & Preterm & Severe abnormalities & Focal, generalised & Status \\
\hline 2 & 23 & 908 & 24 & $\mathrm{IVH}$ & Normal & Focal & $1(21 \mathrm{~s})$ \\
\hline 3 & 30 & 1484 & 30 & $\begin{array}{l}\text { Maternal illness, } \\
\text { possibly drug } \\
\text { induced seizures }\end{array}$ & Normal & Focal & 3 \\
\hline 4 & 28 & 908 & 35 & Meningitis & Severe abnormalities & Multifocal & Status \\
\hline 5 & 25 & 700 & 26 & $\begin{array}{l}\text { Bilateral intraventricular } \\
\text { haemorrhage }\end{array}$ & Severe abnormalities & Generalised & Status \\
\hline 6 & 34 & 2122 & 35 & $\begin{array}{l}\text { Dystonia, cerebellar } \\
\text { hypoplasia }\end{array}$ & Moderate abnormalities & Multifocal & 10 \\
\hline 7 & 40 & 4414 & 40 & HIE & Severe abnormalities & Focal, generalising & 12 \\
\hline 8 & 24 & 795 & 32 & Meningitis & Severe abnormalities & Multifocal & 12 \\
\hline 9 & 36 & 3340 & 39 & Meningitis & Severe abnormalities & Generalised & 3 \\
\hline 10 & 40 & 4240 & 40 & Metabolic & Severe abnormalities & Focal & 5 \\
\hline 11 & 33 & 1460 & 33 & Preterm? drugs & Normal & Focal, generalising & 12 \\
\hline 12 & 33 & 1200 & 34 & IUGR & Moderate abnormalities & Focal, generalising & 12 \\
\hline 13 & 40 & 3944 & 40 & HIE & Moderate abnormalities & Generalised & 2 \\
\hline 14 & 29 & 1340 & 35 & $\mathrm{IVH}$ & Severe abnormalities & Multifocal & 9 \\
\hline 15 & 39 & 3300 & 40 & AVM & Moderate abnormalities & Focal & 8 \\
\hline 16 & 42 & 3562 & 42 & HIE & Mild abnormalities & Focal, generalising & 8 \\
\hline 17 & 25 & 764 & 31 & $\mathrm{IVH}$ & Mild abnormalities & Generalised & 14 \\
\hline 18 & 40 & 4380 & 41 & HIE & Normal & Focal & 2 \\
\hline 19 & 40 & 2680 & 40 & 5th day fits & Normal & Focal, generalising & 2 \\
\hline
\end{tabular}

EEG, Electroencephalography; IVH, intraventricular haemorrhage; HIE, hypoxic ischaemic encephalopathy; AVM, arteriovenous malformation; IUGR, intrauterine growth retardation. 


\begin{tabular}{|c|c|c|c|c|}
\hline & 1 & 2 & 3 & 4 \\
\hline \multicolumn{5}{|l|}{$1 \mathrm{~mm} / \mathrm{min}$} \\
\hline True positive & 5 & 10 & 6 & 8 \\
\hline False positive & 0 & 6 & 0 & 1 \\
\hline True negative & 21 & 15 & 21 & 20 \\
\hline False negative & 14 & 9 & 13 & 11 \\
\hline \multicolumn{5}{|l|}{$2.5 \mathrm{~mm} / \mathrm{min}$} \\
\hline True positive & 6 & 13 & 11 & 11 \\
\hline False positive & 0 & 10 & 6 & 5 \\
\hline True negative & 21 & 11 & 15 & 16 \\
\hline False negative & 13 & 6 & 8 & 8 \\
\hline \multicolumn{5}{|l|}{$5 \mathrm{~mm} / \mathrm{min}$} \\
\hline True positive & 8 & 12 & 10 & 12 \\
\hline False positive & 4 & 12 & 8 & 9 \\
\hline True negative & 17 & 9 & 13 & 12 \\
\hline False negative & 11 & 7 & 9 & 7 \\
\hline
\end{tabular}

Short lived seizures, localised seizures, and seizures of low voltage were often missed by all four observers. Figure 1 shows an example.

\section{DISCUSSION}

Our results show that the CFM was not reliable for the diagnosis of seizure in neonates when interpreted by the nonexpert user. When results were compared with EEG results, a large number of seizures were missed. In general, babies were not considered to have seizures on the CFM traces when there were clear seizures recorded on the simultaneous EEG, although one observer did tend to incorrectly report seizures when there were none. One reason for the disappointing results was the failure to detect short lived seizures, localised seizures, and low amplitude seizures. Indeed, we believe that even "expert" raters would have difficulty in detecting these particular types of seizure, as fig l clearly shows. In our hands, the CFM was an insensitive tool, which tended to underreport seizures. Our results are at variance with other reports, and there are several possible explanations for this. One careful study of the cerebro Trac 2500 included only three babies with seizure, and was mainly aimed at evaluating the effectiveness of this system in the assessment of the background EEG. ${ }^{8}$ Only seizure discharges of more than 30 seconds were detected with the cerebro Trac. Another study enrolled 40 at risk babies, but the initial screen for electrical seizure activity was carried out with CFM, and this would exclude babies in whom this technique did not work from further consideration. ${ }^{9}$ In addition, in this evaluation, the EEG that was used for comparison was made on the same day (but not simultaneously) in only 11 of 40 subjects, and up to a week later in the others. The EEG is continuously evolving in this group of high risk babies, which is why we used completely simultaneous recordings.

We believe that the most likely reason for our disappointing results was that we used inexperienced observers. Others, using more experienced observers, have reported better
A

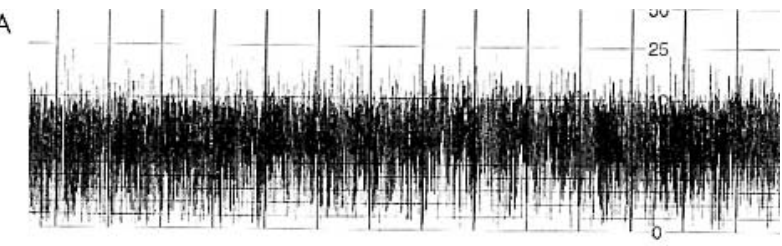

B

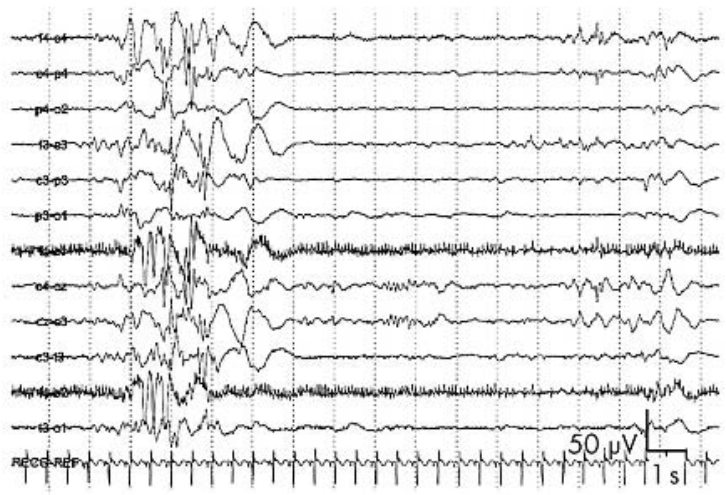

C

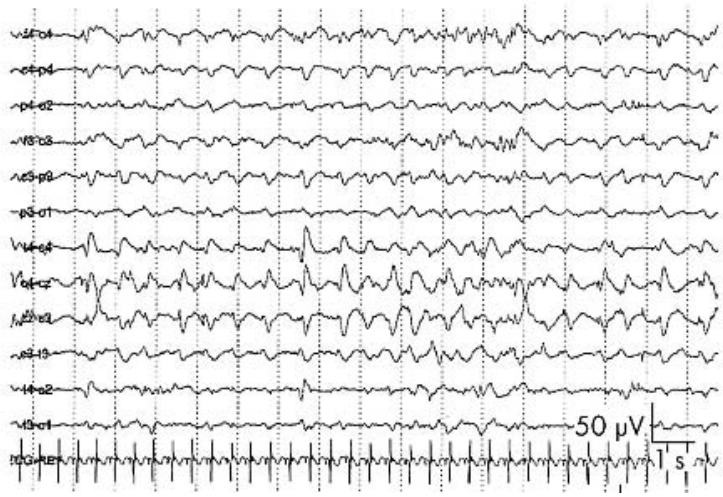

Figure 1 Baby S: a moderately abnormal background electroencephalogram (EEG) with more than 10 seizures an hour which were not detected with the cerebral function monitor (CFM) because they were of low voltage. (A) CFM trace $(6 \mathrm{~cm} / \mathrm{h})$; (B) background EEG pattern; $(C)$ seizures on $E E G$.

results. ${ }^{13}$ However, we used non-expert observers because the CFM is designed to be used by clinicians, who in general have no training in EEG analysis and are given minimal training in reading CFM traces. The individual training given to our observers was probably more than that given to most clinicians who have to interpret CFM traces.

The only other study that attempted to evaluate interobserver error reported a $\kappa$ statistic of 0.76 when two residents and one experienced observer evaluated CFM traces. ${ }^{14}$ We did include five babies with localised seizures, and the constraints of the single channel CFM mean that this technique can never detect seizures that remain localised.

Table 3 Sensitivity, specificity, and interrater agreement at each cerebral function monitor speed

\begin{tabular}{lllll}
\hline $\begin{array}{l}\text { Speed } \\
(\mathbf{m m} / \mathbf{m i n})\end{array}$ & $\begin{array}{l}\text { Sensitivity } \\
(\%)\end{array}$ & $\begin{array}{l}\text { Interrater agreement } \\
\text { (babies with seizure) }\end{array}$ & $\begin{array}{l}\text { Specificity } \\
(\%)\end{array}$ & $\begin{array}{l}\text { Interrater agreement } \\
\text { (babies without seizure) }\end{array}$ \\
\hline 1.0 & 38 & 0.39 & 92 & 0.01 \\
2.5 & 54 & 0.28 & 75 & 0.26 \\
5.0 & 55 & 0.36 & 61 & 0.38 \\
\hline
\end{tabular}


However, focal seizures are common in neonates, in whom stroke is the most common cause of seizures after hypoxic ischaemic encephalopathy. A method that fails to identify focal seizures is thus doomed to failure as a clinical tool in this group.

A further reason for the poor performance of the CFM in our hands may have been that we included preterm babies with moderately abnormal background EEGs, whereas most previous studies have concentrated on term babies. However, in a modern neonatal intensive care unit, a seizure detector must provide robust results across a wide range of gestational ages. Preterm babies are more likely to have seizures than term babies. The vast majority of the babies in this study were over 30 weeks gestation, and detection and treatment of seizures in this group is an important clinical problem.

Finally, and probably most importantly, no previous study has first identified seizures in a population of high risk babies with EEG and then tested the reliability of the CFM. Enrolling babies in whom seizures are detected with the CFM ignores the very population in whom it is unlikely to work, as our study has revealed.

In our view, the single channel CFM is not a suitable tool for the diagnosis of seizures in babies, particularly when used by the non-expert. Our evaluation shows that it is not sensitive enough for clinical reliability. The CFM was not designed as a neonatal seizure detector, and has become adopted for this purpose without sufficient evaluation. If seizures are suspected, a full EEG should be obtained and interpreted by trained neonatal EEG experts. In a unit with a CFM, a simultaneous EEG tracing may show that, in an individual baby, seizures can be detected. When this is known to be the case, the CFM is a useful tool for monitoring the response to treatment. Our work, and that of others, has shown that current anticonvulsant regimens are ineffective, ${ }^{12}{ }^{15}$ and continuous monitoring is undoubtedly the way forward if the hypothesis that better seizure control leads to a better neurodevelopmental outcome is to be pursued. The newer CFMs offer the capability to study up to four channels and to review the raw EEG signal at the cot side. These monitors may perform better in a similarly rigorous analysis in which the original CFM has failed.

\section{ACKNOWLEDGEMENTS}

GB and GC were funded by the National Lotteries Charity Board, via a grant administered by the Fund for Epilepsy. Some of the equipment was purchased with a grant from the Bernard Sunley foundation. We express our appreciation to the babies' parents for allowing us to make video-EEG studies while their babies were ill, and to the clinical team of the Children Nationwide Neonatal Intensive Care Unit.

\section{Authors' affiliations}

J M Rennie, G Chorley, G B Boylan, Department of Child Health, King's College Hospital, London, UK

R Pressler, Y Nguyen, Department of Neurophysiology, King's College Hospital

R Hooper, Department of Public Health Sciences, King's College Hospital

\section{REFERENCES}

1 Levene M. The clinical conundrum of neonatal seizures. Arch Dis Child 2002;86:75-7.

2 Boylan GB, Pressler RM, Rennie JM, et al. Outcome of electroclinical, electrographic, and clinical seizures in the newborn infant. Dev Med Child Neurol 1999;41:819-25.

3 Maynard D, Prior F, Scott FD. Device for continuous monitoring of cerebral activity in resuscitated patients. BMJ 1969;4:545-6.

4 Archbald F, Verma UL, Tejani NA, et al. Cerebral function monitor in the neonate. II. Birth asphyxia. Dev Med Child Neurol 1984;26:162-8.

5 Archbald F, Verma UL, Tejani NA, et al. Cerebral function monitor in the neonate. II. Birth asphyxia. Dev Med Child Neurol 1984;26:162-8.

6 Thornberg E, Ekstrom-Jodal B. Cerebral function monitoring: a method of predicting outcome in term neonates after severe perinatal asphyxia. Acta Paediatr Scand 1994;83:596-601.

7 Hellstrom-Westas L, Rosen I, Svenningsen NW. Predictive value of early continuous amplitude integrated EEG recordings on outcome after severe birth asphyxia in full term infants. Arch Dis Child Fetal Neonatal Ed 1995;72:F34-8.

8 Murdoch-Eaton D, Toet M, Livingston J, et al. Evaluation of the cerebro-trac 2500 for monitoring of cerebral function in the neonatal intensive care. Neuropaediatrics 1984;25:122-8.

9 Klebermass K, Kuhle S, Kohlhauser-Vollmuth C, et al. Evaluation of the cerebral function monitor as a tool for neurophysiological surveillance in neonatal intensive care patients. Child's Nerv Syst 2001;17:544-50.

10 Clancy RR, Legido A. The exact ictal and interictal duration of electroencephalographic neonatal seizures. Epilepsia 1987;28:537-41.

11 Scher MS, Hamid MY, Steppe DA, et al. Ictal and interictal electrographic seizure durations in preterm and term neonates. Epilepsia 1993;34:284-8.

12 Boylan GB, Rennie JM, Pressler RM, et al. Phenobarbitone, neonatal seizures and Video-EEG. Arch Dis Child Fetal Neonatal Ed 2002;86:F165-70.

13 Toet M, Van der Meij W, DeVries L, et al. Comparison between simultaneously recorded amplitude integrated electroencephalogram (cerebral function monitor) and standard electroencephalogram in neonates. Pediatrics 2002; 109:772-9.

14 al Naqeeb N, Edwards AD, Cowan F, et al. Assessment of neonatal encephalopathy by amplitude-integrated electroencephalography. Pediatrics 1999; 103:1263-71.

15 Painter MJ, Scher MS, Stein AD, et al. Phenobarbital compared with phenytoin for the treatment of neonatal seizures. N Engl J Med 1999;341:485-9.

\section{CORRECTION}

The paper by Whitby et al (Low field strength magnetic resonance imaging of the neonatal brain Arch Dis Child Fetal Neonatal Ed 2003;88:F203-F208) was missing an acknowledgement. The authors wish to thank the "Babes in Arms" charity to whom they are extremely grateful for funding the work. 